\title{
Validity and reliability of social anxiety disorder diagnoses in the Swedish National Patient Register
}

\author{
Alba Vilaplana-Pérez ${ }^{1,2,3^{*}}$ (D), Josef Isung ${ }^{1,2}$, Sonja Krig ${ }^{2}$, Sarah Vigerland ${ }^{1,2}$, Maral Jolstedt ${ }^{1,2}$, Johan Bjureberg ${ }^{1,2}$, \\ Jens Högström ${ }^{1,2}$, Kayoko Isomura ${ }^{1,2}$, Daniel Rautio ${ }^{1,2}$, Eva Serlachius ${ }^{1,2}$, Christian Rück ${ }^{1,2}$, David Mataix-Cols , $^{1,2}$ and \\ Lorena Fernández de la Cruz ${ }^{1,2}$
}

\begin{abstract}
Background: Population-based administrative registers are often used for research purposes. However, their potential usefulness depends on the validity of the registered information. This study assessed the validity of the recorded codes for social anxiety disorder (SAD), also known as social phobia, in the Swedish National Patient Register (NPR).

Methods: The personal identification numbers of 300 randomly selected individuals with a diagnosis of SAD recorded in the NPR were obtained from the Swedish National Board of Health and Welfare. The medical files of these individuals were then requested from clinics nationally. A total of 117 files were received and two independent raters reviewed each file to assess the presence or absence of SAD, according to the definition of the International Classification of Diseases, Tenth Edition (ICD-10) and the diagnostic criteria of the Diagnostic and Statistical Manual of Mental Disorders, Fourth Edition, Text Revision (DSM-IV-TR). When disagreements between the two raters were found, a third rater reviewed the file to establish a best estimate diagnosis. Positive predictive values (PPV) and agreement between the two initial raters (using Cohen's kappa) were calculated. Additionally, raters completed the Clinical Global Impression - Severity (CGI-S) and the Global Assessment of Functioning (GAF) rating scales for each file. Inter-rater agreement for the CGI-S and the GAF was assessed using intraclass correlation coefficients (ICC).

Results: After exclusion of files not containing sufficient information, 95 files were included in the analyses. Of these, 77 files (81.05\%) were considered to be 'true positive' cases (PPV $=0.81,95 \%$ confidence interval $=0.72-0.88$ ). Inter-rater agreement regarding the presence or absence of SAD was substantial $(\mathrm{K}=0.72)$. CGI-S and GAF scores indicated that patients were in the moderate range of severity and functional impairment. Inter-rater agreement for the CGI-S and the GAF was moderate to good (ICC $=0.72$ and ICC $=0.82$, respectively).

(Continued on next page)
\end{abstract}

\footnotetext{
* Correspondence: alba.vilaplana@ki.se

${ }^{1}$ Centre for Psychiatry Research, Department of Clinical Neuroscience, Karolinska Institutet, Gävlegatan 22 (Entré B), floor 8, SE-11330 Stockholm, Sweden

${ }^{2}$ Stockholm Health Care Services, Region Stockholm, Stockholm, Sweden

Full list of author information is available at the end of the article
}

(c) The Author(s). 2020 Open Access This article is licensed under a Creative Commons Attribution 4.0 International License, which permits use, sharing, adaptation, distribution and reproduction in any medium or format, as long as you give appropriate credit to the original author(s) and the source, provide a link to the Creative Commons licence, and indicate if changes were made. The images or other third party material in this article are included in the article's Creative Commons licence, unless indicated otherwise in a credit line to the material. If material is not included in the article's Creative Commons licence and your intended use is not permitted by statutory regulation or exceeds the permitted use, you will need to obtain permission directly from the copyright holder. To view a copy of this licence, visit http://creativecommons.org/licenses/by/4.0/ The Creative Commons Public Domain Dedication waiver (http://creativecommons.org/publicdomain/zero/1.0/) applies to the data made available in this article, unless otherwise stated in a credit line to the data. 
(Continued from previous page)

Conclusions: The ICD-10 codes for SAD in the Swedish NPR are generally valid and reliable, but we recommend sensitivity analyses in future register-based studies to minimise the impact of potential diagnostic misclassification. Most patients were moderately severe and impaired, suggesting that results from register-based studies of SAD may be generalizable.

Keywords: Social anxiety disorder, Social phobia, Validity, Reliability, Epidemiology,

\section{Background}

Social anxiety disorder (SAD), also commonly known as social phobia, is one of the most common psychiatric disorders, with an average worldwide lifetime prevalence of $4 \%$ [24]. The disorder is associated with substantial functional impairment $[1,18]$ and presents with a remarkably high degree of comorbidity [2], mainly other anxiety disorders, mood disorders, substance use disorders, and impulse control disorder [21, 24]. While much is known about the clinical features and treatment of $\mathrm{SAD}$, there are important gaps in our understanding of its aetiology and long-term medical and socioeconomic consequences [4].

Swedish nationwide registers - which contain administrative records from entire population 'from cradle to grave' - and a wealth of high-quality healthcare data prospectively collected over several decades, provide unique opportunities to study risk factors as well as the long-term consequences of psychiatric disorders. In 1964, the Swedish National Board of Health and Welfare started the National Patient Register (NPR). This register contains clinical diagnoses by medical specialists, together with administrative data such as hospital or clinic of treatment, dates of admission and discharge, surgical procedures, and patient characteristics including age, sex, and place of residence [16]. At first, the NPR only compiled somatic inpatient care data from six out of 26 Swedish counties, until 1969, when it was complemented with information from psychiatric inpatient units. Since 1984, a mandatory participation for all county councils allowed to connect all data through a 10-digit unique personal identity number given to every Swedish resident, enabling cross-linkage with a range of national registers [17]. Since 2001, the register also includes all outpatient visits from private and public medical doctors (including day surgery and psychiatric care, but excluding primary care). Diagnoses in the NPR are coded according to the Swedish International Classification of Diseases (ICD) system, which was adapted from the World Health Organization ICD classification system [16].

A large variety of epidemiological and genetic studies of psychiatric disorders have been conducted using the NPR, including SAD [11, 15, 23]. However, the usefulness of this research depends on the diagnostic validity of the registered cases [19]. A review showed that the accuracy of a range of diagnostic codes in the NPR, mainly somatic diseases, ranged from 85 to $95 \%$ [16]. In psychiatry, the validity of some diagnostic codes, such as obsessive-compulsive disorder [20], chronic tic disorders [20], schizophrenia [5], bipolar disorder [22], and autism spectrum disorders [10] has been established, while the validity of other diagnoses such as SAD, has not yet been studied.

The aim of this study was to facilitate further epidemiological research using the Swedish NPR by examining the diagnostic validity and reliability of recorded diagnoses for SAD. Additionally, because it cannot be assumed that the patients in the NPR are representative of the general population of individuals with SAD, we rated their symptom severity and global functioning.

\section{Methods}

\section{Procedures}

The study was approved by the regional ethical review board in Stockholm (2012/570-31/1). A request was sent to the Swedish National Board of Health and Welfare to obtain a random sample of 300 personal identification numbers with a record of a SAD diagnosis in the NPR who had been diagnosed anywhere in Sweden. The selection of random cases was undertaken by the Swedish National Board of Health and Welfare without any control or involvement from the study researchers. No weighting or any other adjustments were used to select the cases. The number of requested cases $(n=300)$ was decided on the basis of the response rates in a previous validation study and with the aim of reaching at least 100 cases for analyses [20]. From years 1997 to 2013, a total of 31,975 SAD cases were registered in the NPR, with more than 3000 new cases per year from 2008. The graphic representation of the annual incidence of SAD cases in the NPR is shown in Fig. 1. The steep increase from 2001 was due to the inclusion of the outpatient care services in the NPR.

In order to identify records of SAD, we used the 10th revision of the ICD (ICD-10) code (F40.1), since previous revisions of the manual did not include an independent code for SAD (or 'social phobia', as named in ICD-10). The dates of registered diagnosis spanned from 1998 to 2016 for those with diagnoses in the inpatient register, and from 2001 to 2016 for those in the outpatient register. An ICD-10 


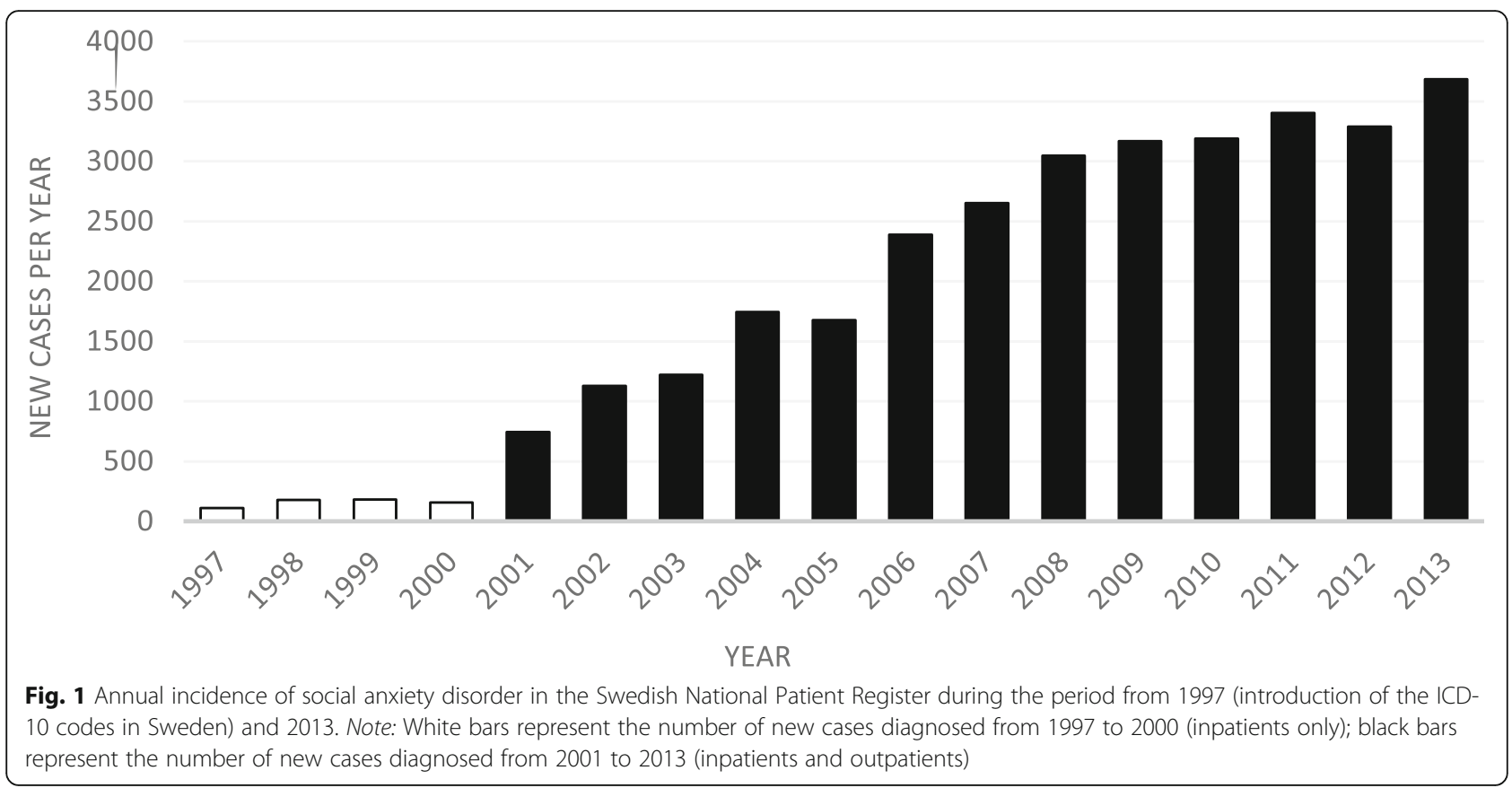

diagnosis of SAD at any time during this time period was sufficient to be eligible for inclusion. The vast majority of the medical files comprised comorbid disorders and therefore contained several ICD psychiatric diagnoses codes. Administrative data including the code of the hospital or clinic where the diagnosis was given was received, together with the personal identification numbers. The full medical files of the randomly selected cases were requested from the corresponding hospitals and clinics via written letters sent through regular mail. For 22 of the 300 cases, we were not able to locate an associated clinic (e.g., the available clinic code corresponded to a clinic that was no longer operative), and therefore requests were only sent for 278 cases. In 144 of these cases, the associated clinics did not reply to the written request, and in 17 additional cases, the associated clinics declined participation. Thus, files for 117 cases were received. Of these, eight cases were excluded after inspection of the patient record, as the SAD diagnosis code was not documented in the actual received file. In a final step, 14 further cases were excluded since there was not enough information in the available material to make a diagnostic judgement (e.g., the diagnostic code was written in the patient record but clinical notes describing symptomatology were not available). Therefore, the total number of available cases for review was 95 . These procedures are similar to those used in previous validation studies using the NPR $[10,20]$. Figure 2 shows the flowchart of cases included in the study.

\section{Chart review}

Each of the 95 medical files available for analysis was assessed by two independent raters using a predefined score sheet (available from the corresponding author upon request). The group of raters performing the chart review was composed of 5 clinical psychologists and 2 psychiatrists, all but one with a $\mathrm{PhD}$ degree, with several years' experience in the assessment and treatment of anxiety disorders.

Raters were independently asked whether the information contained in the patient file was consistent with a probable diagnosis of 'social phobia' in the ICD-10. Further, since the ICD-10 classification does not contain operational diagnostic criteria but, instead, a narrative description of the disorder, raters were further asked whether the individual diagnostic criteria for 'social phobia' were also likely to be met according to the Diagnostic and Statistical Manual of Mental Disorders, Fourth Edition, Text Revision (DSM-IV-TR), allowing for a more systematic and operational evaluation. These judgements were largely based on the direct chart descriptions of significant levels of anxiety in social situations (e.g., nervousness in school or at work related to public speaking, anxiety when attending social events, trouble in socializing with others) and/or descriptions of avoidance of social situations due to these symptoms. Additionally, descriptions of social networks (or the lack of them), difficulties with dating or intimate relationships, evidence of academic or work underachievement or amount of sick leave linked to social anxiety symptoms were essential to assess the symptom severity and degree of functional impairment. When there were disagreements between the two raters regarding the definite or probable presence/absence of SAD, a third independent rater made a final judgement on the diagnostic status of the case. When raters considered that a case did 


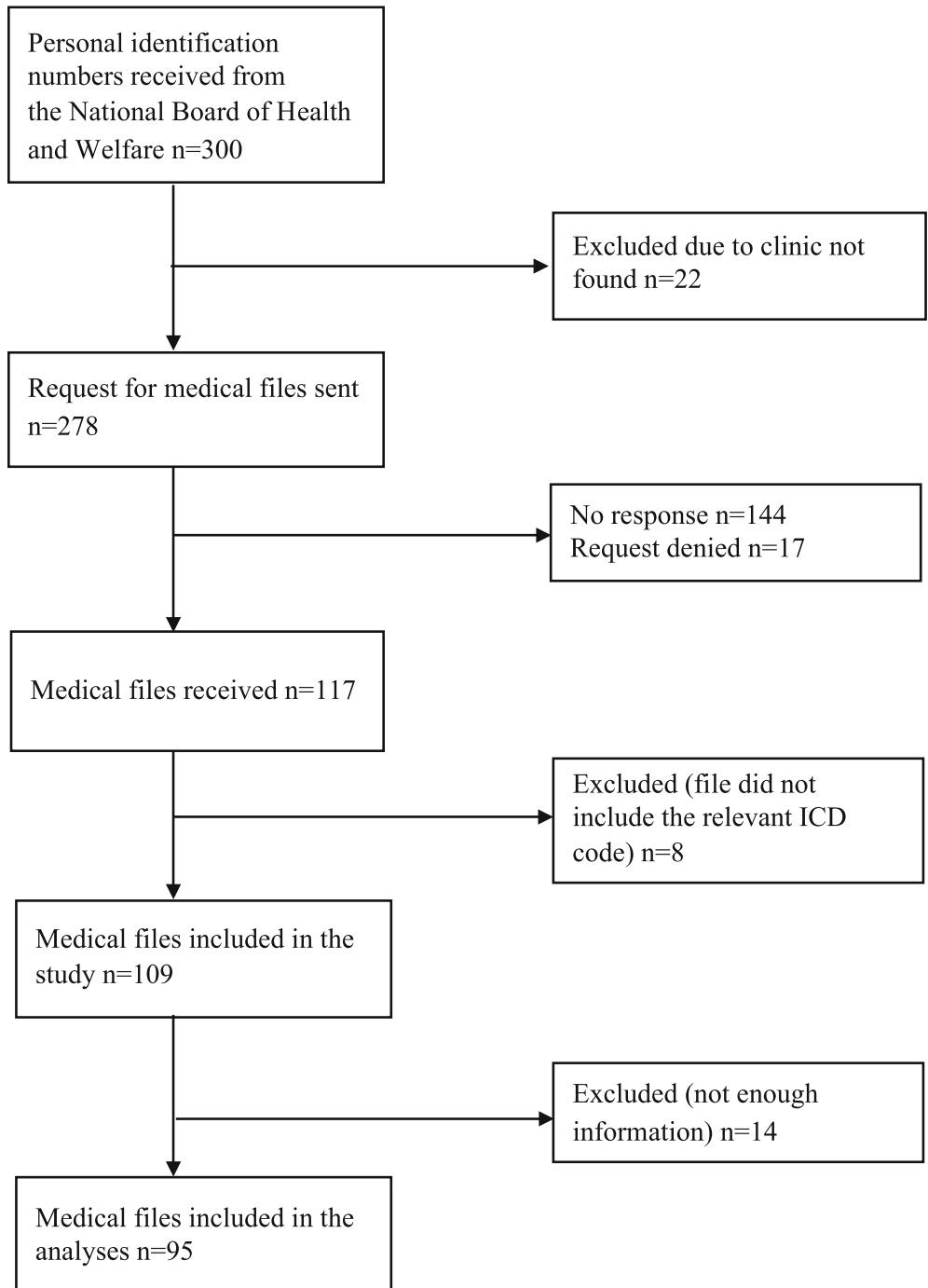

Fig. 2 Flowchart of requested and received patient files containing a social anxiety disorder diagnosis code

not meet SAD criteria (i.e., false positive), they were asked to provide the most plausible alternative diagnosis.

Further, in order to assess SAD symptom severity and global functioning in our sample of cases, raters completed the Clinical Global Impression - Severity (CGI-S) [9] and the Global Assessment of Functioning (GAF) [7] rating scales. The CGI-S is a one-item measure ("Considering your total clinical experience with this particular population, how mentally ill is the patient at this time?') which evaluates the severity of psychopathology (in this case, SAD symptoms) from 1 to 7 , where 1 is 'normal' and 7 is 'among the most extremely ill patients'. This measure has been previously validated for assessing severity of SAD cases [26]. The GAF is also a one-item scale (scores ranging from 1 through 100) used by mental health professionals to subjectively rate the general social, occupational, and psychological functioning of adults [12], where the range 91-100 indicates no symptoms that impair functioning (i.e., superior functioning) and the range 1-10 implies an extremely low functioning with persistent danger for self or others. The GAF has shown good validity and reliability in the assessment of overall functioning in psychiatric patients [12]. Both of these scales are generally rated in reference to the time of the evaluation (or the week before). In this case, and for the purposes of the study, raters were asked to rate these measures averaging the severity and functioning of the patient for the whole time frame covered in each of the assessed files.

\section{Statistical analyses}

We calculated the positive predictive value (PPV) of the SAD diagnosis, that is, those cases diagnosed correctly divided by the sum of the true positives (e.g., the file was 
labelled as SAD and the raters agreed on the diagnosis) and the false positives (i.e., the file was labelled as SAD but the raters did not agree with this judgement), with their corresponding 95\% confidence intervals (CIs). When rater 1 and rater 2 did not agree on the diagnosis, the judgement of a third rater was used as the best estimate diagnosis against the diagnosis in the file. Interrater reliability was calculated using the Cohen's kappa statistic [3] with the ratings of the two initial raters. To assess the inter-rater agreement for the CGI-S and the GAF scales, intraclass correlation coefficients (ICC) with 95\% CIs were calculated based on a mean-rating $(k=7)$, average measures, and 2-way mixed-effects model [13]. SPSS statistical package version 25 (SPSS Inc., Chicago, IL) was used for all the analyses.

\section{Results}

\section{Validity and reliability of SAD codes in the NPR}

A total of 95 cases (53 females, 56\%), all from psychiatric clinics across the country, were included in the analyses. Of these, 77 (81\%) were deemed as 'true positive' cases since raters considered that either the ICD-10 definition or the DSM-IV-TR diagnostic criteria for SAD were met. In most cases (94\%), criteria were met according to both diagnostic systems. In the small number of cases where there was a discordance between diagnostic systems, raters considered that the ICD-10 definition was met, but not the most stringent DSM-IV-TR criteria.

The 77 'true positive' cases corresponded to a PPV of 0.81 (95\% CI, 0.72-0.88). The remaining 18 cases were not considered to fulfil neither ICD-10 nor DSM-IV-TR criteria for SAD and were, therefore, considered false positive cases. The most frequent alternative diagnoses were other anxiety disorders, depression, and autism spectrum disorders (Table 1).

The Cohen's kappa between the two initial raters regarding the presence or absence of a social anxiety disorder was 0.72. Of the 7 cases where there was a disagreement between raters, four cases were added to the final number of true positives (i.e., the third rater considered that the SAD diagnosis was present) and three were deemed false positives (i.e., the third rater considered that the SAD diagnosis was absent) after the best estimate diagnosis review.

Of the 77 'true positive' cases, 71 had obtained a CGI$\mathrm{S}$ and GAF score from the raters (in the remaining six cases, raters had not scored the scales and therefore this information was missing). Regarding the CGI-S, the mean score was $4.27(\mathrm{sd}=0.70)$ for rater 1 and $4.15(\mathrm{sd}=$ 0.62 ) for rater 2 , indicating moderate severity of the assessed cases (Fig. 3). The inter-rater agreement for the CGI-S was moderate (ICC $=0.72$ [95\% CI, 0.54-0.82]). For the GAF, the mean score was $52.1(\mathrm{sd}=8.77)$ for rater 1 and $53(\mathrm{sd}=9.0)$ for rater 2 , indicating moderate difficulty in social, occupational, or school functioning (Fig. 3). The inter-rater agreement for the GAF was good $(\mathrm{ICC}=0.82$ [95\% CI, 0.71-0.89]).

\section{Discussion}

The Swedish NPR includes more than 30,000 individuals with a diagnosis of SAD until 2013, and approximately 3000 new patients are added to the register each year. Therefore, the NPR constitutes a potentially unique resource for high quality epidemiological research into this disorder. However, before such research can be conducted, it is important to formally validate the corresponding ICD codes, which mainly rely on clinicians' judgements and therefore may be biased or inaccurate. Reassuringly, our results showed that the diagnostic validity of SAD in the NPR is generally good, with a PPV of 0.81 when rating the overall occurrence of SAD through chart review, the gold standard method for confirming diagnoses [25]. Further, the inter-rater agreement for the disorder was substantial [14]. The validity of the SAD diagnosis is comparable to that of other psychiatric disorders in the NPR, including bipolar disorder $(\mathrm{PPV}=$ 0.81-0.91) [22], schizophrenia (PPV $=0.91-1.0) \quad$ [6], obsessive-compulsive disorder (PPV $=0.55-0.96)[20]$ or tic disorders $(\mathrm{PPV}=0.86-0.97)$ [20].

In our sample, $19 \%$ of the cases were regarded as false positives (i.e., expert raters did not agree with the recorded diagnoses). The most frequent alternative

Table 1 Alternative diagnoses for false positive cases $(n=18)$

\begin{tabular}{ll}
\hline Alternative diagnoses & Frequency \\
\hline Anxiety or post-traumatic stress disorder (other than social anxiety disorder) & 7 \\
Depression & 5 \\
Autism spectrum disorder & 3 \\
Bipolar disorder & 2 \\
Eating disorder & 2 \\
Attention-deficit/hyperactivity disorder & 1 \\
Psychotic disorder & 1
\end{tabular}

Note: Numbers do not add up to the total of false positive cases $(n=18)$ since, for some cases, raters suggested more than one alternative diagnosis 


\section{CGI-S}

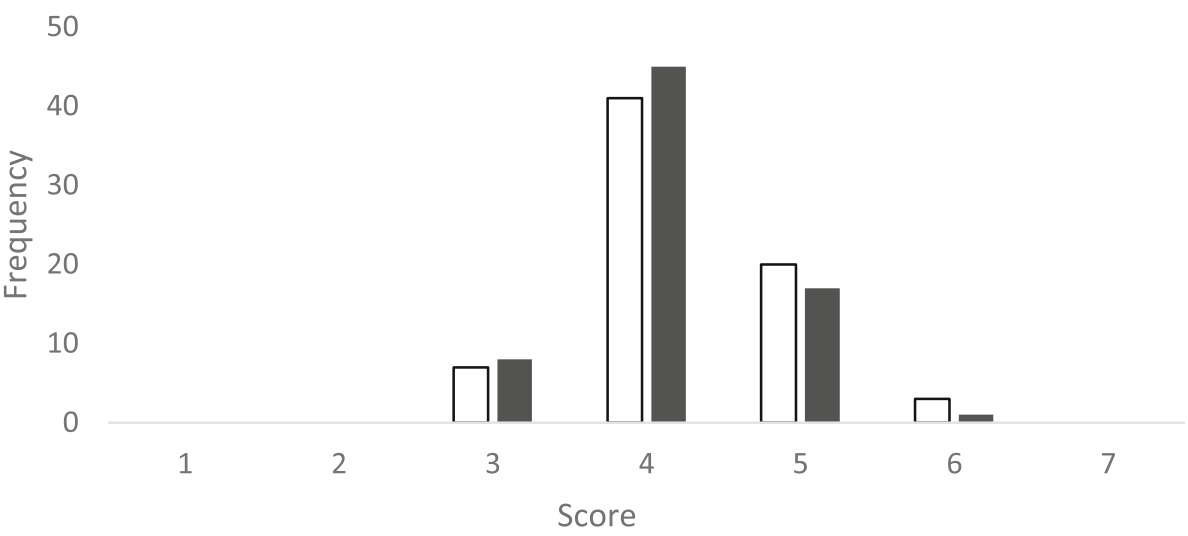

$\square$ Rater $1 \square$ Rater 2

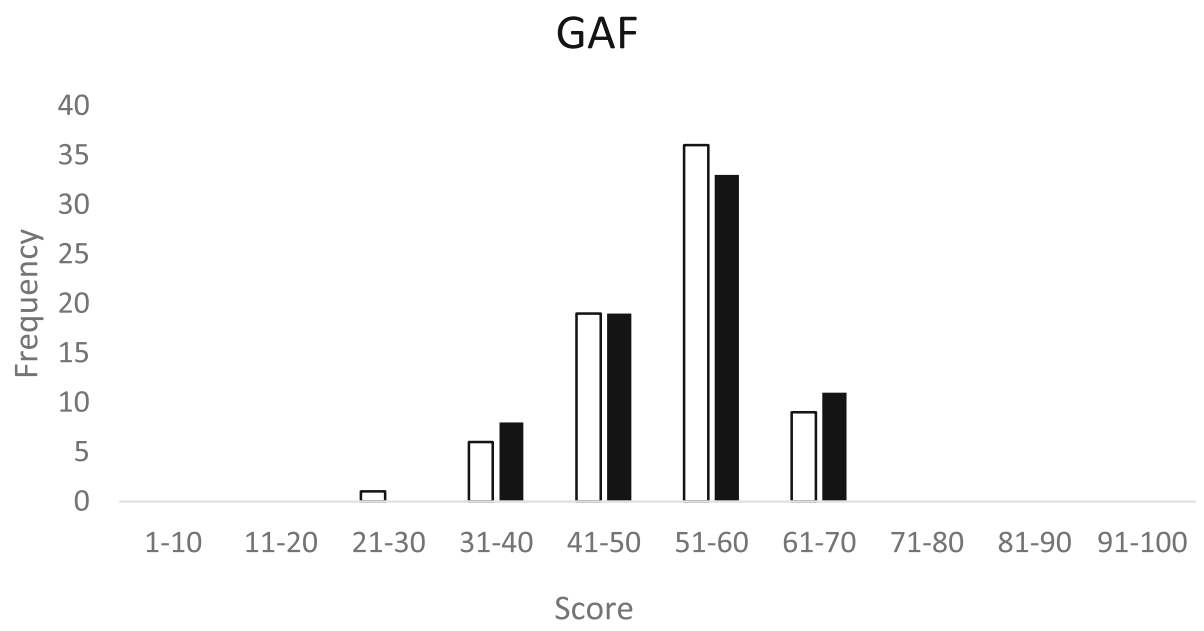

Rater 1

Rater 2

Fig. 3 Score distribution of the Clinical Global Impression - Severity (CGI-S) and Global Assessment of Functioning (GAF), by rater

diagnoses were other anxiety disorders and mood disorders, which share clinical features with SAD, as well as the underlying dimensions of distress or negative affect, shared genetic predisposition and neurobiology [8]. Since misclassification was not uncommon, we recommend that future register-based studies of SAD be always accompanied with sensitivity analyses whereby different comorbidities are systematically excluded to evaluate their impact on the outcomes of interest.

Since the NPR only includes diagnoses given by specialists, it is often assumed that patients included in this register are at the most severe end of the spectrum, potentially affecting the generalizability of the register-based results to other populations (e.g., those being seen in primary care settings). However, our severity and global functioning measures were fairly normally distributed, with most patients belonging to the moderately ill category of the CGI-S and the moderate difficulty in social, occupational or school functioning of the GAF. Thus, the results of register-based studies of SAD are likely to generalise reasonably well to other treatment-seeking populations.

The main strength of this study is the random selection of cases diagnosed with SAD from clinics placed all over the country. The medical files were meticulously evaluated by independent and skilled clinical psychologists or psychiatrists in accordance with both ICD-10 descriptions and DSM-IV-TR diagnostic criteria for SAD. However, the study is not without limitations. First, we were only able to collect and therefore assess about one third of the initially requested cases, which may suggest a potential selection bias of unknown nature. Potential differences (e.g., in demographic or clinical variables) 
between the available files and those that could not be obtained could not be examined since individual information (beyond the personal identification number, the year of diagnosis, and the clinic that assigned the diagnosis) was not made available to us because it was not covered by our ethical approval for this study. However, the main reasons why we did not receive the files were mainly practical (e.g., some of the clinics did no longer exist, had confidentiality concerns or no administrative personnel was available to copy and post the files). Thus, although we cannot be certain, we believe that systematic bias is unlikely. Additionally, some of the files received did not contain sufficient information to make a decision on diagnosis; based on previous studies using similar methods [10, 20], we decided to exclude these files from the analyses, as considering them as either true positives or false positives would carry a substantial risk of reporting inaccurate PPVs. Second, because the study did not include control groups (i.e., medical records from patients without $\mathrm{SAD}$ ), the raters were not blind to the register diagnoses, which may have increased the risk of bias towards confirming the SAD diagnoses. Lastly, raters scored the CGI and the GAF based on the chart review, without directly interviewing the patients. The validity of these scales when used in this format is unknown and, therefore, the results should only be viewed as broad clinical impressions of the patients' severity and general function. Nonetheless, the inter-rater agreement was adequate for both instruments.

\section{Conclusions}

The ICD-10 codes for SAD cases in the Swedish NPR are generally valid and reliable but we recommend sensitivity analyses in future register-based studies to minimise the impact of potential diagnostic misclassification. Most patients were moderately severe and impaired, suggesting that the results of register-based studies of SAD may be generalizable to other treatment-seeking populations.

\section{Abbreviations \\ CGI-S: Clinical global impression - severity; DSM-IV-TR: Diagnostic and Statistical Manual of Mental Disorders, Fourth Edition, Text Revision: GAF: Global assessment of functioning; ICC: Intraclass correlation coefficients; ICD-10: International Classification of Diseases, Tenth Edition; NPR: National patient register; PPV: Positive predictive value; SAD: Social anxiety disorder}

\section{Acknowledgements}

None.

\section{Authors' contributions}

LFC, DMC, ES, CR, and JH were involved in the conception of the research question and designed the study protocol. SK was the data manager and administrator for the project. JI, SV, MJ, JB, JH, KI, and DR were independent raters in the chart review. AVP contributed to the data management and performed the statistical analyses. AVP and LFC drafted the manuscript. LFC and DMC provided supervision. All authors contributed to the final version of the manuscript by providing substantial intellectual contributions. The authors read and approved the final manuscript.

\section{Funding}

This study was supported by a grant from the Stockholm County Council (reference number 20180078) awarded to LFC. AVP was supported by a fellowship from the Alicia Koplowitz Foundation.

The funders had no role in the design and conduct of the study; collection, management, analysis, and interpretation of the data; preparation, review, or approval of the manuscript; and decision to submit the manuscript for

publication. Open access funding provided by Karolinska Institute.

Availability of data and materials

No additional data are available.

Ethics approval and consent to participate

The study was approved by the regional ethical review board in Stockholm $(2012 / 570-31 / 1)$.

\section{Consent for publication}

Not applicable.

\section{Competing interests}

JB receives book royalties from Natur \& Kultur. DMC receives royalties for contributing articles to UpToDate, Wolters Kluwer Health and Elsevier. LFC receives royalties for contributing articles to UpToDate, Wolters Kluwer Health. The rest of authors declare that they have no competing interests to declare.

\section{Author details}

${ }^{1}$ Centre for Psychiatry Research, Department of Clinical Neuroscience, Karolinska Institutet, Gävlegatan 22 (Entré B), floor 8, SE-11330 Stockholm, Sweden. 'Stockholm Health Care Services, Region Stockholm, Stockholm, Sweden. ${ }^{3}$ Departament de Personalitat, Avaluació i Tractaments Psicològics, Universitat de València, València, Spain.

Received: 3 October 2019 Accepted: 30 April 2020

Published online: 15 May 2020

References

1. Aderka IM, Hofmann SG, Nickerson A, Hermesh H, Gilboa-Schechtman E, Marom S. Functional impairment in social anxiety disorder. J Anxiety Disord. 2012;26(3):393-400. https://doi.org/10.1016/j.janxdis.2012.01.003.

2. Chartier MJ, Walker JR, Stein MB. Considering comorbidity in social phobia. Soc Psychiatry Psychiatr Epidemiol. 2003;38(12):728-34. https://doi.org/10. 1007/s00127-003-0720-6.

3. Cohen. Coefficient of agreement for nominal scales. Educ Psychol Meas. 1960;20:37-46.

4. Craske MG, Stein MB. Anxiety. Lancet. 2016;388(10063):3048-59. https://doi. org/10.1016/S0140-6736(16)30381-6.

5. Dalman C, Broms J, Cullberg J, Allebeck P. Young cases of schizophrenia identified in a national inpatient register. Soc Psychiatry Psychiatr Epidemiol. 2002;37(11):527-31. https://doi.org/10.1007/s00127-002-0582-3.

6. Ekholm B, Ekholm A, Adolfsson R, Vares M, Osby U, Sedvall GC, et al. Evaluation of diagnostic procedures in Swedish patients with schizophrenia and related psychoses. Nord J Psychiatry. 2005;59(6):457-64. https://doi.org/ 10.1080/08039480500360906.

7. Endicott J, Spitzer RL, Fleiss JL, Cohen J. The global assessment scale: a procedure for measuring overall severity of psychiatric disturbance. JAMA Psychiat. 1976;33(6):766-71. https://doi.org/10.1001/archpsyc.1976. 01770060086012

8. Goodwin GM. The overlap between anxiety, depression, and obsessivecompulsive disorder. Dialogues Clin Neurosci. 2015;17(3):249-60.

9. Guy W, National Institute of Mental, H., Psychopharmacology Research, B., \& Division of Extramural Research, P. ECDEU assessment manual for psychopharmacology : 1976. Rockville: National Institute of Mental Health; 1976.

10. Idring S, Rai D, Dal H, Dalman C, Sturm H, Zander E, et al. Autism Spectrum disorders in the Stockholm youth cohort: design, prevalence and validity (Stockholm youth cohort design). PLoS One. 2012;7(7):e41280. https://doi. org/10.1371/journal.pone.0041280.

11. Isomura K, Boman M, Ruck C, Serlachius E, Larsson H, Lichtenstein P, et al. Population-based, multi-generational family clustering study of social 
anxiety disorder and avoidant personality disorder. Psychol Med. 2015;45(8): 1581-9. https://doi.org/10.1017/S0033291714002116.

12. Jones SH, Thornicroft G, Coffey M, Dunn G. A brief mental health outcome scale-reliability and validity of the global assessment of functioning (GAF). $\mathrm{Br}$ J Psychiatry. 1995;166(5):654-9. https://doi.org/10.1192/bjp.166.5.654.

13. Koo TK, Li MY. A guideline of selecting and reporting Intraclass correlation coefficients for reliability research. J Chiropr Med. 2016;15(2):155-63. https:// doi.org/10.1016/j.jcm.2016.02.012.

14. Landis JR, Koch GG. The measurement of observer agreement for categorical data. Biometrics. 1977;33(1):159-74.

15. Lichtenstein P, Halldner L, Zetterqvist J, Sjolander A, Serlachius E, Fazel S, et al. Medication for attention deficit-hyperactivity disorder and criminality. N Engl J Med. 2012;367(21):2006-14. https://doi.org/10.1056/ NEJMoa1203241.

16. Ludvigsson Andersson E, Ekbom A, Feychting M, Kim JL, Reuterwall C, et al. External review and validation of the Swedish national inpatient register. BMC Public Health. 2011;11:450. https://doi.org/10.1186/1471-2458-11-450

17. Ludvigsson JF, Otterblad-Olausson P, Pettersson BU, Ekbom A. The Swedish personal identity number: possibilities and pitfalls in healthcare and medical research. Eur J Epidemiol. 2009;24(11):659-67. https://doi.org/10.1007/ s10654-009-9350-y.

18. McKnight PE, Monfort SS, Kashdan TB, Blalock DV, Calton JM. Anxiety symptoms and functional impairment: a systematic review of the correlation between the two measures. Clin Psychol Rev. 2016;45:115-30. https://doi.org/10.1016/j.cpr.2015.10.005.

19. Rosén M. National Health Data Registers: a Nordic heritage to public health. Scand J Public Health. 2002;30(2):81-5. https://doi.org/10.1177/ 14034948020300020101

20. Rück C, Larsson KJ, Lind K, Perez-Vigil A, Isomura K, Sariaslan A, et al. Validity and reliability of chronic tic disorder and obsessive-compulsive disorder diagnoses in the Swedish National Patient Register. BMJ Open. 2015;5(6) e007520. https://doi.org/10.1136/bmjopen-2014-007520.

21. Ruscio AM, Brown TA, Chiu WT, Sareen J, Stein MB, Kessler RC. Social fears and social phobia in the USA: results from the National Comorbidity Survey Replication. Psychol Med. 2008;38(1):15-28. https://doi.org/10.1017/ s0033291707001699.

22. Sellgren C, Landen M, Lichtenstein P, Hultman CM, Langstrom N. Validity of bipolar disorder hospital discharge diagnoses: file review and multiple register linkage in Sweden. Acta Psychiatr Scand. 2011;124(6):447-53. https://doi.org/10.1111/j.1600-0447.2011.01747.x.

23. Song H, Fang F, Tomasson G, Arnberg FK, Mataix-Cols D, Fernández de La Cruz $\mathrm{L}$, et al. Association of stress-related disorders with subsequent autoimmune disease. JAMA. 2018;319(23):2388. https://doi.org/10.1001/jama. 2018.7028

24. Stein Lim CCW, Roest AM, de Jonge P, Aguilar-Gaxiola S, Al-Hamzawi A, et al. The cross-national epidemiology of social anxiety disorder: data from the world mental health survey initiative. BMC Med. 2017;15(1):143. https:// doi.org/10.1186/s12916-017-0889-2

25. Worster A, Haines T. Advanced statistics: understanding medical record review (MRR) studies. Acad Emerg Med. 2004;11(2):187-92. https://doi.org/ 10.1111/j.1553-2712.2004.tb01433.x.

26. Zaider Tl, Heimberg RG, Fresco DM, Schneier FR, Liebowitz MR. Evaluation of the clinical global impression scale among individuals with social anxiety disorder. Psychol Med. 2003;33(4):611-22.

\section{Publisher's Note}

Springer Nature remains neutral with regard to jurisdictional claims in published maps and institutional affiliations.

Ready to submit your research? Choose BMC and benefit from:

- fast, convenient online submission

- thorough peer review by experienced researchers in your field

- rapid publication on acceptance

- support for research data, including large and complex data types

- gold Open Access which fosters wider collaboration and increased citations

- maximum visibility for your research: over $100 \mathrm{M}$ website views per year

At BMC, research is always in progress.

Learn more biomedcentral.com/submissions 